\title{
Concentrations, Possible Sources and Health Risk of Heavy Metals in Multi-Media Environment of the Songhua River, China
}

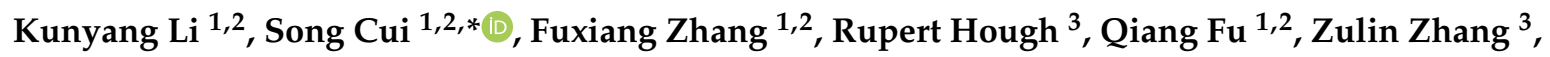 \\ Shang Gao ${ }^{1,2}$ and Lihui An $4, *$ (iD \\ 1 International Joint Research Center for Persistent Toxic Substances (IJRC-PTS), School of Water Conservancy \\ and Civil Engineering, Northeast Agricultural University, Harbin 150030, China; kunyleee@163.com (K.L.); \\ ZhangFuxiang823@163.com (F.Z.); ijrc_pts_neau_paper@yahoo.com (Q.F.); 13204665308@163.com (S.G.) \\ 2 Research Center for Eco-Environment Protection of Songhua River Basin, Northeast Agricultural University, \\ Harbin 150030, China \\ 3 The James Hutton Institute, Craigiebuckler, Aberdeen AB15 8QH, UK; Rupert.Hough@hutton.ac.uk (R.H.); \\ Zulin.Zhang@hutton.ac.uk (Z.Z.) \\ 4 State Key Laboratory of Environmental Criteria and Risk Assessment, Chinese Research Academy of \\ Environmental Sciences, Beijing 100012, China \\ * Correspondence: cuisong-bq@neau.edu.cn (S.C.); anlhui@163.com (L.A.); Tel.: +86-451-5519-0568 (S.C.); \\ Fax: +86-451-5519-0568 (S.C.)
}

Received: 9 February 2020; Accepted: 5 March 2020; Published: 9 March 2020

\begin{abstract}
Heavy metal pollution in the river environment has been a source of widespread interest due to potential threats to human health and ecosystem security. Many studies have looked at heavy metal pollution in the context of single source-pathway-receptor relationships, however few have sought to understand pollution from a more wholistic multi-media perspective. To investigate potential risks in a more wholistic way, concentrations of six heavy metals $(\mathrm{Cd}, \mathrm{Cr}, \mathrm{Ni}, \mathrm{Cu}, \mathrm{Zn}$ and $\mathrm{Pb})$ were detected in multi-media (water, sediment and riparian soil) collected from 14 sampling sites in the main stream of the Songhua River. Chemical analyses indicated that the average concentration of heavy metals in water followed: $\mathrm{Zn}>\mathrm{Cr}>\mathrm{Cu}>\mathrm{Pb}>\mathrm{Ni}>\mathrm{Cd}$, with a different trend observed in sediments and riparian soil: $\mathrm{Zn}>\mathrm{Cr}>\mathrm{Ni}>\mathrm{Pb}>\mathrm{Cu}>\mathrm{Cd}$. The potential risk was evaluated using the heavy metal pollution index $(H P I)$, Nemerow pollution index $\left(P_{N}\right)$, hazard index $(H I)$ and carcinogenic risk $(C R)$ metrics. Results showed that all HPI values were lower than the critical level of 100 indicating that the levels of these targeted heavy metals were within drinking water safety limits. The $P_{N}$ indicated that both sediment (2.64) and soil (2.95) could be considered "moderately polluted", with $\mathrm{Cd}$ and $\mathrm{Zn}$ providing the most significant contributions. A human health risk assessment suggested that the non-carcinogenic risks were within acceptable levels $(H I<1)$, as was the cancer risk associated with dermal adsorption $\left(C R<10^{-6}\right)$. However, the $C R$ associated with ingestion exposure $\left(4.58 \times 10^{-6}\right)$ exceeded the cancer risk threshold $\left(10^{-6}\right)$ indicative of elevated cancer incidence in exposed populations. Health-risk estimates were primarily associated with $\mathrm{Cd}$ in the Songhua River. Source apportionment was informed by Pearson correlation analysis coupled with principal component analysis (PCA) which indicated that $\mathrm{Cu}$ was mainly derived from natural (geogenic) sources; $\mathrm{Cr}$ and $\mathrm{Ni}$ were associated with industrial emissions; $\mathrm{Pb}$ might be derived from agricultural and transportation sources; $\mathrm{Zn}$ might be from industrial, agricultural activities and transportation; while $\mathrm{Cd}$ is likely from industrial and agricultural emissions. The source apportionment information could provide the basis for a risk-management strategy focused on reducing $\mathrm{Cd}$ and $\mathrm{Zn}$ emissions to the riverine environment. Results from this study will provide the scientific knowledge that is needed for measuring and controlling heavy metals sources and pollution characteristics, and identifying the potential cancer risk with different exposure pathways, as well as making effective environmental management policies at catchment or regional scales.
\end{abstract}


Keywords: heavy metals; Songhua River; multi-media environment; health risk; source apportionment

\section{Introduction}

Heavy metals are ubiquitous pollutants in the environment, derived from both geogenic and anthropogenic sources [1-3]. Heavy metals have been the subject of significant attention due to their environmental toxicity, bioaccumulation and persistence [2,3]. Excessive emissions and accumulation of heavy metals can cause serious pollution to environmental media such as air, soil, water and sediments, with potential implications for ecological safety and human health [4-6].

Rivers are an extremely important freshwater resource and ecological system that humans are often reliant upon $[1,6,7]$. However, rapid development of industry, agriculture and urbanization often results in polluting discharges (e.g., wastewater, agricultural run-off) to watercourses that impact water quality, with knock-on implications for ecosystem and human health $[3,8,9]$. Sediments are generally considered as both "source" and "sink" for most heavy metals and other pollutants in the water environment, thus measurements made in sediments can be a useful indicator of potential ecological risk to the aquatic environment [10-13]. Similarly, soil can also be an important storage reservoir of pollutants, which can enter soil through wastewater discharge, atmospheric deposition and fertilizer application [14-16]. Contaminated soils can subsequently pollute the riverine environment via runoff to surface water and via leaching to groundwater $[16,17]$. Therefore, water, sediment, and soil are not independent media, but components of a wholistic system that people are also a component of. People depend on this environment for basic provisioning services and are, therefore, simultaneously impacted through exposure to any heavy metals present in that environment.

The human health risk assessment approach developed by the United States Environmental Protection Agency (USEPA) has been used extensively to estimate the potential health risk [4-6,18]. In general terms, this is a hazard-based approach which defines 'risk' as the ratio between an exposure and a pre-determined 'safe' level for that exposure. These 'safe' levels are sometimes outcome-specific cf. reference dose vs. cancer slope factor. In China, the USEPA methodology has been used to estimate human health risks associated with specific high-profile water pollution events in the Yellow River, Pearl River, Yangtze River and Xiangjiang River $[4,7,9,17]$. However, these studies are limited by adopting the single source-pathway-receptor paradigm of the USEPA methodology which can poorly reflect the comprehensive human health risk [4,5,14]. In non-occupational settings, it has been demonstrated that exposure is not dominated by a single pathway or exposure media [19]. Therefore, a comprehensive human health risk assessment that integrates all important exposure pathways within the multi-media environment is needed to improve confidence in risk estimates.

The Songhua River is one of the seven largest rivers in China, and an important source of drinking and irrigation water, as well as water abstraction for industrial production $[19,20]$. The land use of the Songhua catchment is dominated by intensive cereal production and also includes a number of primary and secondary heavy industries (petrochemical, coal mining, mechanical processing, etc.) [20-23]. Discharges and run-off from these industries to both surface water and groundwater often contain heavy metals. Long-term exposure can have adverse impacts on the environment and human health. Research on heavy metals in the Songhua River Basin has received much attention, but is currently restricted to studying the ecological risks and impacts associated with heavy metals in sediments [21,22]. Therefore, there is an imperative to widen our knowledge to include multi-media (water, sediments and soils) sources and sinks of heavy metals and to understand potential exposure and risk levels from a more comprehensive range of pathways. Hence, the purpose of this study is: (1) to analyze the characteristics of heavy metal pollution in water, sediments and riparian soil of the Songhua River; (2) to assess the overall pollution level of heavy metals in using the heavy metal pollution index (HPI) method and the Nemerow pollution index method $\left(P_{N}\right)$; (3) to estimate daily heavy metal intake $(C D I)$ 
under different exposure pathways, and evaluate associated health risks for residents of the riparian zone; and (4) to analyze possible sources of pollution using Pearson correlation analysis coupled with principal component analysis $(P C A)$. The results of this study will provide the scientific basis for developing a multi-media, multi-pathway exposure risk model. For the specific case of heavy metals, it provides a scientific rationale for identifying their spatial distribution and sources within the multi-media environment, as well as the important exposure pathways and associated risks.

\section{Materials and Methods}

\subsection{Study Area}

The Songhua River, the largest tributary of Heilongjiang River in China, flows through Heilongjiang Province and Jilin Province [20]. The average annual temperature is $3-5^{\circ} \mathrm{C}$, and the freezing period is 5 months (from November to March next year) in the watershed [21]. The main stream of Songhua River $\left(124^{\circ} 39^{\prime}-132^{\circ} 31^{\prime} \mathrm{E}\right.$ and $\left.45^{\circ} 26^{\prime}-47^{\circ} 43^{\prime} \mathrm{N}\right)$ has a drainage area of approximately $1.893 \times 10^{5} \mathrm{~km}^{2}$ and a total length of $939 \mathrm{~km}$. The abundant incoming water is the main irrigation water source in the Sanjiang Plain and the Songnen Plain $[19,20]$. At the same time, the Songhua River Basin is an important catchment for agricultural production (primarily cereals and other combinable crops), as well as being an industrial and energy base in China [21,23]. Influenced by the topographical features of the main stream of the Songhua River and the distribution of major cities and counties along the river bank, 14 sampling points were selected in July 2015, as shown in Figure 1 and Table S1 (presented in Supplementary Information).



Figure 1. Locations of sampling sites of the Songhua River.

\subsection{Heavy Metal Analysis}

\subsubsection{Sample Collection and Processing}

We refer to the Technical Specifications for Surface Water and Wastewater Monitoring (HJ_T91-2002) [24]. Five sub-sampling points within $30 \mathrm{~m}$ of each pre-set sampling location (Figure 1) 
were randomly selected. From each location, water was collected using polyethylene plastic bottles previously washed with nitric acid. During sampling, care was taken to avoid agitation of sediment on the riverbed. Collected samples were acidified with Nitric acid to bring the $\mathrm{pH}$ down to less than 2 . Surface sediment $(0-10 \mathrm{~cm})$ was collected using a grab sampler from the 14 sampling sites using the same approach as for the water samples. For sediments, the five sub-samples were combined into a single representative sample per site. Each sample was stored in a pre-washed glass container with a Teflon cap. At the same time, riparian soil samples $(0-20 \mathrm{~cm})$ were also collected within $30 \mathrm{~m}$ at water sampling sites using a stainless steel scoop that had been prewashed with deionized water and stored in a pre-washed glass container. Any debris such as weeds and gravel from solid samples (sediment samples were allowed to stand before pouring off the overlying water) was removed manually. All samples were transported to the International Joint Research Center for Persistent Toxic Substances laboratory at Northeast Agricultural University (IJRC-PTS, NEAU) in Harbin where they were stored in a refrigerator prior to analyses.

Sample processing was undertaken in accordance with the Environmental Quality Standard for Soil Environmental Quality Risk Control Standard for Soil Contamination of Agricultural Land (GB15618-2018) [25] and Water and Wastewater Monitoring and Analysis Methods (Fourth Edition) [26]. Briefly, soil and sediment samples were air-dried at room temperature and passed through a 20 mesh $(0.84 \mathrm{~mm})$ nylon screen. Sieved samples were then ground to a particle size of less than $0.25 \mathrm{~mm}$ with an agate mortar. $500 \mathrm{~mL}$ water samples were placed on a heating plate and concentrated by evaporation to $50 \mathrm{~mL}$ for use. Soil and sediment samples were digested in a Teflon crucible by the wet oxidation method ( $\mathrm{HCl}-\mathrm{HNO}_{3}-\mathrm{HClO}_{4}-\mathrm{HF}$ ) (GR, Tianjin Yaohua Chemical Reagent Co., Ltd., Tianjin, China) until no obvious solid particles remained [8]. Digestates were assayed for heavy metal content using a Thermo Fisher Scientific atomic absorption spectrophotometer (ICE 3500), the flame portion was used to determine the contents of $\mathrm{Cu}, \mathrm{Cr}, \mathrm{Zn}$, and $\mathrm{Ni}$, and the graphite furnace portion was used to determine the contents of $\mathrm{Cd}$ and $\mathrm{Pb}$.

\subsubsection{Quality Assurance and Quality Control (QA/QC)}

Strict quality assurance and control of all analytical data was conducted. The glass and polyethylene vessels used were fully soaked in $2 \mathrm{~mol} \mathrm{~L}^{-1} \mathrm{HNO}_{3}$ for more than $24 \mathrm{~h}$, washed with ultrapure water and dried before use. The water used in the analysis was ultrapure water and the reagents used were excellent grade pure. Blank and standard samples were digested and analyzed using the same procedure. Standard reference materials (GBW07305 and GBW07458) were obtained from the Chinese Academy of Measurement Science. The recovery rate ranged from $93.7 \%$ to $102.5 \%$. The standard deviations between parallel samples were less than $5 \%$. It was guaranteed that the correlation coefficient of calibration curves of the 6 heavy metals was greater than 0.9995 .

\subsection{Evaluation Pollution of Heavy Metals}

\subsubsection{Heavy Metal Pollution Index}

The heavy metal pollution index (HPI) indicated the relative total water quality determined based on all selected parameters [27]. The HPI provides an estimate of the comprehensive impact of each individual heavy metal on the overall water quality, and is determined as follows:

$$
\begin{gathered}
H P I=\frac{\sum\left(Q_{i} W_{i}\right)}{\sum W_{i}} \\
Q_{i}=\frac{C_{i}}{S_{i}} \times 100 ; W_{i}=\frac{k}{S_{i}}
\end{gathered}
$$

where $Q_{i}$ is a sub-indicator of the heavy metal pollution index, $W_{i}$ is the unit weight of the heavy metal parameter, $C_{i}$ is the concentration value of the $i$-th heavy metal parameter $\left(\mathrm{mg} \mathrm{L}^{-1}\right)$, and $S_{i}$ is the highest standard permissible value of the $i$-th parameter, The Standards for Drinking Water Quality 
(GB5749-2006) [28] was selected as the source of the highest allowable level for each of the heavy metal of interest. The proportional constant $(k)$ was set to 1 [3]. The allowable and critical HPI value of drinking water is usually 100 [27]. Based on this, the categories of HPI are summarized in Table S2.

\subsubsection{Nemerow Pollution Index}

The Nemerow pollution index $\left(P_{N}\right)$ can not only comprehensively reflect the pollution level of a given area, but also highlight the environmental hazard of the most significant pollutants within a given sampling scheme [29-31]. Values of $P_{N}$ for soil and sediment can be calculated using the following equations:

$$
\begin{gathered}
P_{N}=\sqrt{\frac{\left.P_{i(\max )}^{2}+P_{i(a v e)}\right)^{2}}{2}} \\
P_{i}=\frac{C_{i}}{S_{i}} \\
P_{i(a v e)}=\frac{1}{n} \sum_{n}^{1} P_{i}
\end{gathered}
$$

where $P_{N}$ is the pollution index of each sampling site, $P_{i}$ is the single contamination factor of the $i$-th heavy metal, $P_{i \text { (ave) }}$ is the arithmetic mean of the single contamination factor of all heavy metals, $P_{i(\text { max })}$ the maximum contamination factor among the heavy metals, $C_{i}$ is the measured concentration of heavy metal and $S_{i}$ represents the quality standard value of different heavy metals. The risk screening values from the background value of soil in Heilongjiang province [32] were used for $S_{i}$. Values of $S_{i}$ for $\mathrm{Cu}, \mathrm{Cr}, \mathrm{Zn}, \mathrm{Pb}, \mathrm{Ni}$, and $\mathrm{Cd}$ were thus $20,58.6,70.7,24.2,22.8$ and $0.086 \mathrm{mg} \mathrm{kg}^{-1}$, respectively. The evaluated criteria of $P_{N}$ are classified in Table S3.

\subsubsection{Human Health Risk Assessment}

Ingestion and dermal absorption, the most common and important exposure pathways for soil and water in the living environment [3,14], were selected for human health risk assessment. The US Environmental Protection Agency (USEPA) points out that the amount of pollutants absorbed by the human body is calculated based on chronic daily intake (CDI) [33].

For the water and soil, the CDI was defined as Equations (6)-(9) [5,33]:

$$
\begin{gathered}
C D I_{w-\text { in }}=\frac{C_{i} \times I R \times A B S_{g} \times E F \times E D}{A T \times B W} \\
C D I_{w-\text { derm }}=\frac{C_{i} \times S A \times K_{p} \times A B S_{d} \times E T \times E F \times E D \times C F}{A T \times B W} \\
C D I_{\text {s-in }}=\frac{C_{i} \times I R \times E F \times E D}{A T \times B W} \times C F \\
C D I_{\text {s-derm }}=\frac{C_{i} \times S A \times S L \times A B S_{d} \times E F \times E D}{A T \times B W} \times C F
\end{gathered}
$$

where $C D I$ refers to the exposure doses from ingestion and dermal absorption $\left(\mathrm{mg} \mathrm{kg}^{-1} \mathrm{~d}^{-1}\right), C_{i}$ was the average concentration of the heavy metal $i$ in water $\left(\mathrm{mg} \mathrm{L}^{-1}\right), C F$ was conversion factor. The remaining parameters and source of parameters are shown in Table 1. 
Table 1. Exposure parameters in the health risk model.

\begin{tabular}{|c|c|c|c|c|}
\hline \multirow{2}{*}{ Exposure Parameter } & \multicolumn{2}{|r|}{ Water } & \multicolumn{2}{|c|}{ Soil } \\
\hline & Unit & Reference & Unit & Reference \\
\hline Ingestion rate $(I R)[19,34]$ & $\mathrm{Ld} \mathrm{d}^{-1}$ & 1.227 & $\mathrm{mg} \mathrm{d}^{-1}$ & 100 \\
\hline Exposure frequency $(E F)$ & day & 365 & day & 365 \\
\hline Exposure duration $(E D)[21]$ & a & 74.8 & $\mathrm{a}$ & 74.8 \\
\hline Daily exposure time $(S L)[35]$ & hr day ${ }^{-1}$ & 0.6 & - & - \\
\hline Average weight Body weight $(B W)$ [19] & $\mathrm{kg}$ & 63.1 & $\mathrm{~kg}$ & 63.1 \\
\hline Average life time $(A T)[21]$ & $\mathrm{d}$ & 27,302 & $\mathrm{~d}$ & 27,302 \\
\hline Conversion factor Conversion factor $(C F)$ & $\mathrm{L} \mathrm{cm}^{-3}$ & $10^{-6}$ & $\mathrm{mg} \mathrm{kg}^{-1}$ & $10^{-6}$ \\
\hline Skin exposed area Skin-surface area $(S A)$ [35] & $\mathrm{cm}^{2}$ & 18,100 & $\mathrm{~cm}^{2}$ & 18,100 \\
\hline Permeability coefficient $\left(K_{p}\right)$ [35] & $\mathrm{cm} \mathrm{hr}^{-1}$ & $\begin{array}{c}\mathrm{Pb}: 10^{-4} ; \mathrm{Cd}: 10^{-3} \\
\mathrm{Cr}: 2 \times 10^{-3} ; \mathrm{Zn}: \\
6 \times 10^{-4} ; \mathrm{Ni}: 2 \times 10^{-4} \\
\mathrm{Cu}: 10^{-3}\end{array}$ & - & - \\
\hline Gastrointestinal absorption factor $\left(A B S_{g}\right)[35]$ & - & $\begin{array}{c}\mathrm{Pb}: 0.117 ; \mathrm{Cd}: 0.05 ; \\
\mathrm{Cu}: 0.3 ; \mathrm{Zn}: 0.2 ; \mathrm{Ni}: 0.2 \\
\text { Cr:0.038 }\end{array}$ & - & - \\
\hline Skin adhesion factor $(S L)[35]$ & - & - & $\mathrm{mg} \mathrm{cm}^{-2} \mathrm{~d}^{-1}$ & 0.2 \\
\hline Dermal absorption factor $\left(A B S_{d}\right)[35]$ & - & 0.001 & - & - \\
\hline
\end{tabular}

The cancer risk $(C R)$ indicates the incidence of cancer that exceeds expected levels in a person's lifetime by exposure to some certain carcinogenic substances with Equation (10):

$$
C R=C D I \times S F
$$

where $S F$ is the cancer slope factor $\left(\mathrm{mg}^{-1} \mathrm{~kg}\right.$ day). The acceptable level of a $C R$ value was usually between $10^{-6}$ and $10^{-4}$ [35]. When values of $C R$ exceed $10^{-4}$ this indicates a high cancer risk to humans, while values of $C R$ between $10^{-6}$ and $10^{-4}$ indicate a lower but elevated cancer risk.

The potential non-carcinogenic risks were assessed by hazard quotient $(H Q)$ as Equation (5) [35]. When values of $H Q$ were $>1$, non-carcinogenic effects should be considered.

$$
H Q=\frac{C D I}{R f D}
$$

where $R f D$ represents the heavy metal intake reference dose $\left(\mathrm{mg} \mathrm{kg}^{-1} \mathrm{day}^{-1}\right)$, in this study all values of $R f D$ used were those published by the USEPA [36]. It should be noted that all RfDs published by the USEPA use dose estimates based on typical American body weights and are, therefore, likely to underestimate risk in Asian populations [18]. In addition, the total potential non-carcinogenic risks caused by different pathways were assessed by Hazard Index (HI) as Equation (12):

$$
H I=\sum H Q=H Q_{d e r m}+H Q_{i n}
$$

where $H Q_{\text {derm }}$ and $H Q_{\text {in }}$ represent the hazard quotient $(H Q)$ caused by dermal absorption and ingestion pathway, respectively. Similarly, if the $H I$ were $>1$, adverse effects on human health should be considered [35]. Both $\mathrm{HI}$ and $C R$ were calculated using the parameters summarized in Table 1 to reflect the potential health risks of the residents in the study area.

\subsubsection{Statistical Analysis}

The normality test was performed by Kolmogorov-Smirnov test for each trace metal; One-sample T-test was used to compare the concentrations of heavy metals in individual environmental media 
with background value; The inter group difference was compared with the independent sample T-test; Pearson correlation analysis was combined with principal component analysis $(P C A)$ to identify the source of pollution. Prior to this, the validity of PCA was tested by Kaiser-Meyer-Olkin (KMO) values $(>0.5)$ and Bartlett Sphericity test $(p<0.01)$ [12,19], All mathematical and statistical calculations were performed by Excel 2016, Origin 8.6 and SPSS 21.0, with sample distributions plotted using ArcGIS 10.2 .

\section{Results and Discussion}

\subsection{Concentrations and Spatial Distribution of Heavy Metals}

\subsubsection{Concentration}

The heavy metal contents and statistical characteristics of the Songhua River water, sediments and riparian soil are shown in Table 2. The average concentrations in water followed: $\mathrm{Zn}>\mathrm{Cr}>\mathrm{Cu}>\mathrm{Pb}>\mathrm{Ni}>\mathrm{Cd}$, and these levels were significantly higher than the background concentrations found in the Songhua River $(p<0.01)$ [37]. For example, $\mathrm{Zn}\left(64.25 \mu \mathrm{g} \mathrm{L}^{-1}\right)$ and $\mathrm{Cr}(12.10$ $\mu \mathrm{g} \mathrm{L}^{-1}$ ) were 16.56 and 14.13 times as high as the background values [37]. The concentration of $\mathrm{Cd}$ was at least $0.26 \mu \mathrm{g} \mathrm{L}^{-1}$ and 4.07 times greater than the reported background value. Levels of $\mathrm{Zn}$ in the Songhua River water were even higher than those reported from the Hun River [38], a catchment strongly impacted by sewage sludge applications to land, but were generally lower than levels of $\mathrm{Zn}$ measured in the Xiangjiang River flowing through Hunan Province (in which there are non-ferrous metals) [4]. All monitoring activities reported on here were in compliance with the requirements of the Environmental quality standards for surface water (GB3838-2002) for the secondary protection zone of centralized drinking water for surface water source [39]. Although there are elevated levels of pollution in the Songhua River compared to the reported background values, water quality is still adequate for irrigation based on current standards.

Table 2. Statistical characteristics of heavy metal content in Songhua River.

\begin{tabular}{|c|c|c|c|c|c|c|c|}
\hline Medium & Element & Range & Average & Median & $\begin{array}{l}\text { Standard } \\
\text { Deviation }\end{array}$ & $\begin{array}{l}\text { Coefficient of } \\
\text { Variation }\end{array}$ & $\begin{array}{c}\text { Background } \\
\text { Values }[32,37]\end{array}$ \\
\hline \multirow{6}{*}{ Water $\mu g \mathrm{~L}^{-1}$} & $\mathrm{Cu}$ & $0.75-7.55$ & 4.27 & 4.06 & 1.90 & $44.5 \%$ & 1.46 \\
\hline & $\mathrm{Cr}$ & $5.71-28.23$ & 12.01 & 10.10 & 6.16 & $51.3 \%$ & 0.85 \\
\hline & $\mathrm{Zn}$ & $17.29-116.01$ & 64.25 & 59.13 & 29.49 & $45.9 \%$ & 3.88 \\
\hline & $\mathrm{Pb}$ & $1.66-6.27$ & 3.02 & 2.92 & 1.04 & $34.4 \%$ & 1.76 \\
\hline & $\mathrm{Ni}$ & $0.50-3.07$ & 1.68 & 1.49 & 0.66 & $39.2 \%$ & 1.02 \\
\hline & $\mathrm{Cd}$ & ND-0.46 & 0.26 & 0.25 & 0.09 & $42.1 \%$ & 0.06 \\
\hline \multirow{6}{*}{$\begin{array}{l}\text { Sediment mg } \\
\mathrm{kg}^{-1}\end{array}$} & $\mathrm{Cu}$ & $7.94-23.88$ & 14.57 & 13.30 & 4.66 & $32.0 \%$ & 20 \\
\hline & $\mathrm{Cr}$ & $33.66-88.99$ & 63.97 & 60.62 & 16.24 & $25.4 \%$ & 58.6 \\
\hline & $\mathrm{Zn}$ & $100.69-326.14$ & 175.76 & 159.35 & 64.11 & $36.5 \%$ & 70.7 \\
\hline & $\mathrm{Pb}$ & $7.88-23.44$ & 16.84 & 17.60 & 4.16 & $24.7 \%$ & 24.2 \\
\hline & $\mathrm{Ni}$ & $13.47-35.41$ & 22.71 & 21.77 & 5.77 & $25.4 \%$ & 22.8 \\
\hline & $\mathrm{Cd}$ & $1.17-5.82$ & 0.28 & 0.26 & 0.13 & $45.2 \%$ & 0.086 \\
\hline \multirow{6}{*}{$\begin{array}{l}\text { Riparian soil } \\
\mathrm{mg} \mathrm{kg}^{-1}\end{array}$} & $\mathrm{Cu}$ & $10.83-30.78$ & 18.27 & 18.52 & 5.19 & $28.4 \%$ & 20 \\
\hline & $\mathrm{Cr}$ & 16.79-105.90 & 74.26 & 77.20 & 21.66 & $29.2 \%$ & 58.6 \\
\hline & $\mathrm{Zn}$ & $81.40-255.18$ & 145.83 & 135.42 & 44.01 & $30.2 \%$ & 70.7 \\
\hline & $\mathrm{Pb}$ & $9.27-28.41$ & 18.82 & 18.54 & 4.15 & $22.0 \%$ & 24.2 \\
\hline & $\mathrm{Ni}$ & $14.20-31.13$ & 23.79 & 23.97 & 5.64 & $23.7 \%$ & 22.8 \\
\hline & $\mathrm{Cd}$ & $0.37-0.87$ & 0.31 & 0.25 & 0.20 & $66.2 \%$ & 0.086 \\
\hline
\end{tabular}

The average concentrations of heavy metals in sediments were: $\mathrm{Zn}>\mathrm{Cr}>\mathrm{Ni}>\mathrm{Pb}>\mathrm{Cu}>\mathrm{Cd}$. The contents of heavy metals in sediments such as $\mathrm{Zn}\left(175.76 \mathrm{mg} \mathrm{kg}^{-1}\right)$ and $\mathrm{Cd}\left(0.28 \mathrm{mg} \mathrm{kg}^{-1}\right)$ were significantly higher than the background concentrations in the soils of Heilongjiang Province $(p<0.01)$ [32]. A number of monitoring sections returned concentrations of Cd (S1, S9, S10, S12) and $\mathrm{Zn}(\mathrm{S} 1, \mathrm{~S} 7, \mathrm{~S} 10, \mathrm{~S} 12)$ in excess of the risk screening value of the Environmental Quality Standard (GB15618-2018) [25]. Concentrations of $\mathrm{Pb}$ were lower than those reported in a previous study of the 
Songhua River, while levels of $\mathrm{Zn}$ were greater [40]. Compared to the water analysis, the relative concentrations of the heavy metals in sediment still indicated that $\mathrm{Zn}$ and $\mathrm{Cd}$ were at the extremes of the distribution; however, some differences were seen in the relative ranking of the other 4 metals. Heavy metals in sediments tend to be the result of long-term accumulation $[12,13]$, while heavy metal contents in surface water more closely reflect contemporary pollution within the catchment, thus explaining the relative differences seen between water and sediments. Compared with sediments in other rivers (Table $\mathrm{S} 4$ ), the contents of $\mathrm{Cu}, \mathrm{Cr}, \mathrm{Zn}, \mathrm{Ni}$ and $\mathrm{Pb}$ in the Songhua River were significantly lower than those in the Yangtze River $(p<0.01)$ [11], while the concentrations of heavy metals were higher than those in many major European rivers such as the Ebro River and Seine River [41,42].

The average concentration of heavy metal in the riparian soil was $\mathrm{Zn}>\mathrm{Cr}>\mathrm{Ni}>\mathrm{Pb}>\mathrm{Cu}>\mathrm{Cd}$, and consistent with the trends seen in the sediment data. The contents of $\mathrm{Ni}, \mathrm{Pb}$ and $\mathrm{Cu}$ were close to background values reported for Heilongjiang Province [32], however, $\mathrm{Cd}\left(0.31 \mathrm{mg} \mathrm{kg}^{-1}\right)$ and $\mathrm{Zn}$ $\left(145.83 \mathrm{mg} \mathrm{kg}^{-1}\right)$ were 3.59 and 2.06 times higher than their background values, respectively $(p<0.01)$. These monitoring data suggest that both $\mathrm{Cd}$ and $\mathrm{Zn}$ have accumulated to a certain extent. The average concentration of $\mathrm{Cd}$ measured in this study was higher than the median value, indicating that there was a sampling location or locations with significantly elevated levels of Cd pollution, such as S6 and S10, which had significant leverage on the dataset. The coefficient of variation of $\mathrm{Cd}$ in soil was higher than that of sediment and water, which may suggest some differences in sources. With the exception of $\mathrm{Zn}$, the contents of heavy metals in soil were higher than those in sediments in the Songhua River, and this might be associated with atmospheric deposition. A study on heavy metal sources in the Songnen Plain of Heilongjiang Province found that atmospheric deposition was a significant input pathway by which $\mathrm{Cd}, \mathrm{Cu}, \mathrm{Pb}$ and $\mathrm{Zn}$ enter surface waters, accounting for $78 \%-98 \%$ of the total input [43].

\subsubsection{Spatial Distribution}

The spatial distribution of heavy metal contents of water, sediments and riparian soil in the Songhua River is shown in Figure 2. The maximum concentration of $\mathrm{Zn}$ and $\mathrm{Cd}$ were found in water at Harbin section (S4 and S5), which was significantly higher than other locations $(p<0.01)$, while the highest concentrations of the other heavy metals were detected in Yilan County (S9) characterized by agricultural non-point sources as well as a few point source discharges. For the sediment at site S9, the concentrations of $\mathrm{Cd}, \mathrm{Cu}$ and $\mathrm{Zn}$ are evaluated as being 'high level'. Given these metals are used as an additive in commonly used insecticides and fertilizers, the inference is that agricultural activities are likely important pollution sources in this location. Considering the sediment samples, points S3 and $S 8$ are located in rural areas where the heavy metal contents were far lower compared to samples from S4, S5, S11 and S12 that are all close to urban areas $(p<0.05)$. The proximity of urban areas to the riparian zone influences both the magnitude and spatial distribution of heavy metal pollution [44].

\subsection{Pollution Assessment of Heavy Metals}

The Songhua River is a major source of both potable and irrigation water for residents within the riparian zone. Therefore, the most stringent drinking water guidelines (GB5749-2006) and background values were taken as references in this study $[28,32]$. The distribution of the HPI and $P_{N}$ are shown in Figure 3. The HPI of water samples from the Songhua River was less than 100, indicating that the water is suitable for drinking. [27]. Given that $\mathrm{Pb}$ and $\mathrm{Cd}$ can cause both acute and chronic toxic effects on the human body even at very low levels, and thus they were considered as the main contributors to the HPI in the present study, with average contribution rates of $60.4 \%$ and $21.6 \%$, respectively. The average HPI was 13.5, which was at the "low" level, but it was close to the "medium" level (HPI = 15). Downstream of Harbin City, levels of heavy metal pollution gradually increased (S3-S6), indicating that intensive human activities could lead to the increasing trace elements in the water. The HPI value was especially acute at location $\mathrm{S} 6$ which was influenced by Harbin City (upstream) as well as by diffuse sources from adjacent agricultural land. 

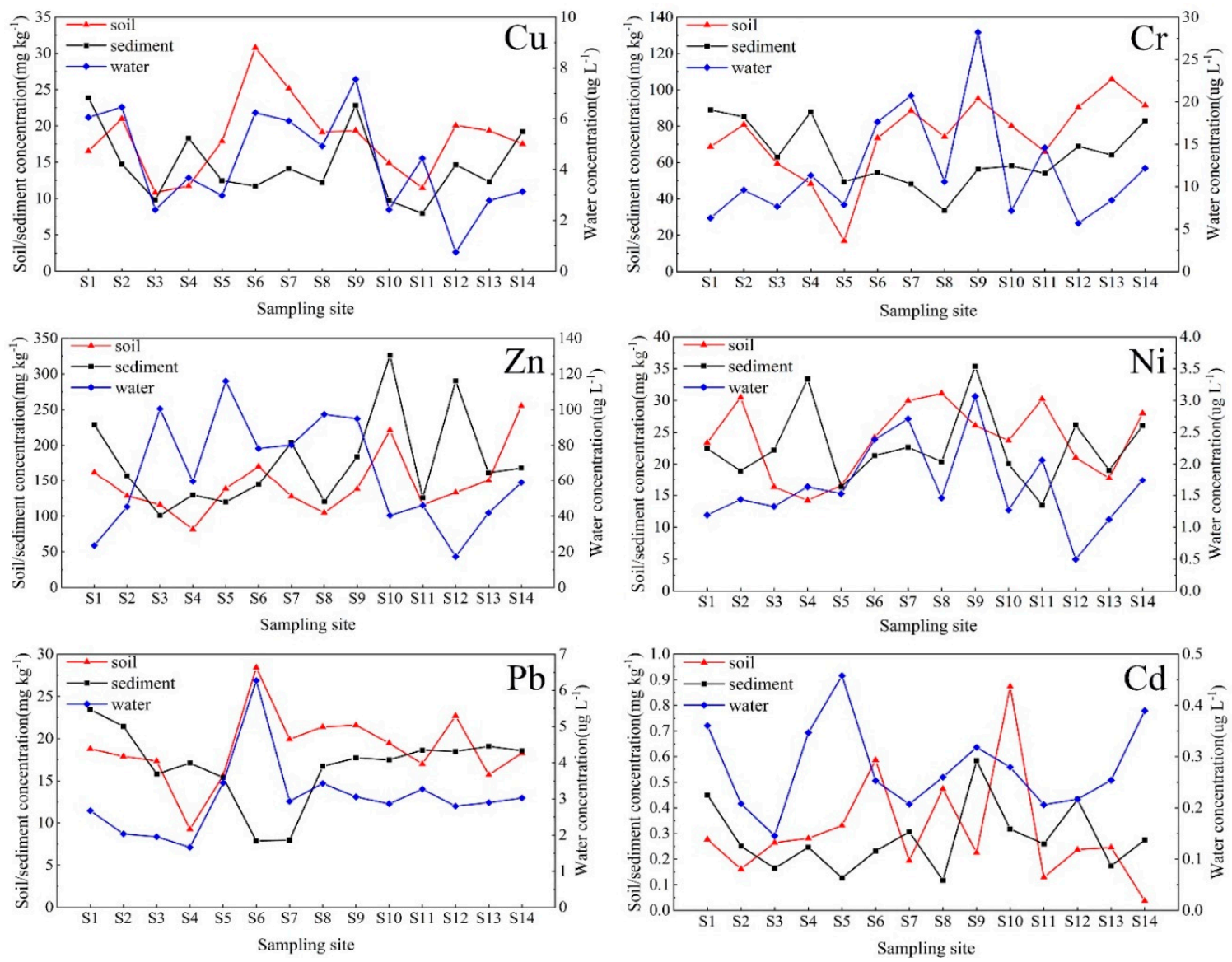

Figure 2. Concentration of $\mathrm{Cu}, \mathrm{Cr}, \mathrm{Zn}, \mathrm{Ni}, \mathrm{Pb}$ and $\mathrm{Cd}$ in the water, sediment and riparian soil.

According to the pollution assessment standard proposed by Nemerow [29], the average of the single factor pollution index $\left(P_{i}\right)$ of the six heavy metals in sediments and riparian soil has the same order: $\mathrm{Cd}>\mathrm{Zn}>\mathrm{Cr}>\mathrm{Ni}>\mathrm{Cu}>\mathrm{Pb}$ (Table S5), indicating "Severe pollution" by $\mathrm{Cd}\left(P_{i}>3\right)$ and "moderate pollution" by $\mathrm{Zn}\left(2<P_{i} \leq 3\right)$. Overall, levels of pollution in the riparian soils were greater than those derived for the sediment samples. The $P_{i}$ value of $\mathrm{Cd}$ was significantly elevated compared to the other heavy metals $(p<0.05)$. Cd is generally derived from industrial emissions and coal combustion, as well as the application of fertilizers (especially for phosphate fertilizers) $[4,8]$. The $P_{N}$ values are an indicator of the comprehensive pollution of multiple heavy metals. The $P_{N}$ of soil and sediments for all sampling sites ranged from 1.41 to 7.46 and 1.39 to 5.07 , with an average of 2.95 and 2.64 , respectively, which were considered to be "moderately polluted" $\left(2.5<P_{N} \leq 7\right)$. The results indicated that there were locations where pollution levels could be considered to be significantly elevated including riparian soils from S6, S8 and S10 $(p<0.05)$ and sediments from S1, S9, S10 and S12 $(p<0.05)$. It might be strategic to focus on these locations as part of future environmental monitoring and pollution prevention efforts. In addition, the $P_{i}$ of $\mathrm{Cd}$ in riparian soil is 3.54 times greater than the $P_{i(\text { ave })}$ at site $\mathrm{S} 10$, which suggests the presence of a specific point source or sources. Overall, values of $H P I$ of water indicated that $\mathrm{Cd}$ and $\mathrm{Pb}$ were the main contributors to the derived level of pollution; while values of $P_{N}$ indicated that $\mathrm{Cd}$ and $\mathrm{Zn}$ were the most important pollution factors both in sediments and riparian soil. 


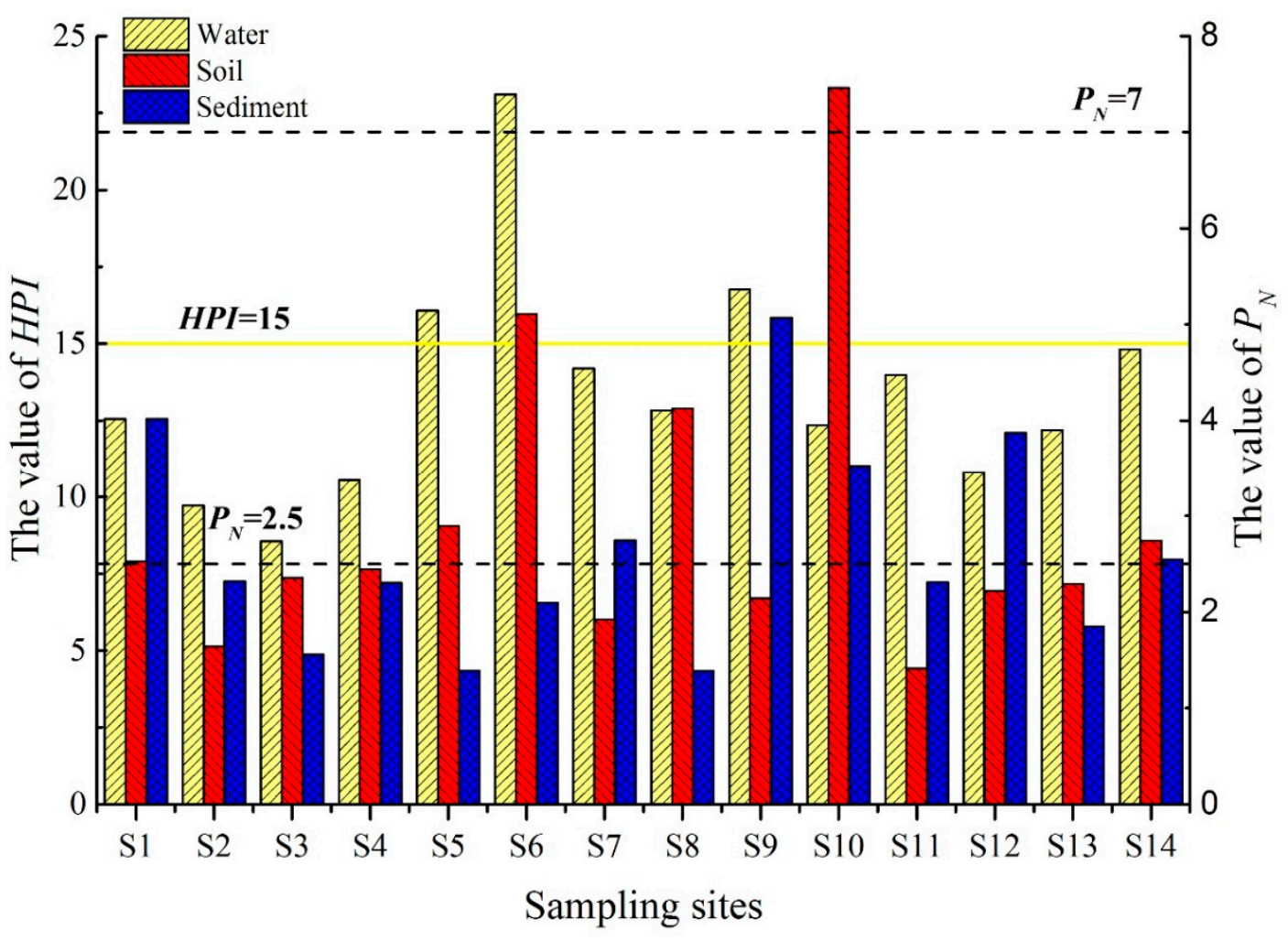

Figure 3. Heavy metal pollution index $(H P I)$ of water, Nemerow pollution index $\left(P_{N}\right)$ of sediment and riparian soil in Songhua River.

\subsection{Human Health Risk Assessment}

Among the environmental media we studied, surface water and soil were directly exposed to pollutant inputs and also acted as secondary sources, as well as being important media as carriers of pollutants within specific human exposure pathways. Indices of health risk including $H I$ and $C R$ were calculated for ingestion and dermal absorption exposure pathways (Table 3). Despite $\mathrm{Cr}$ and $\mathrm{Pb}$ accounting for the bulk of the non-carcinogenic risk, values of $H I$ were considered to be within acceptable levels. Although the HPI and $P_{N}$ indicated that levels of Pb pollution in the catchment were low, its potential health risk to humans was indicated as being more significant highlighting the non-linear relationship between environmental levels and the magnitude of exposure. Given the importance of $\mathrm{Cd}$ as the main driver of the carcinogenic risk estimates, the $C R$ values of $C d$ were only calculated for cancer risk assessment in this study. Although the cancer risk from dermal absorption $\left(1.08 \times 10^{-7}\right)$ could be considered to be within appropriate limits of safety, the cancer risk from ingestion (average of $4.58 \times 10^{-6}$ ) across all sampling sites indicates elevated cancer risk. Values of $C R$ for ingestion exceeded $10^{-6}$ at every single sampling location.

Compared with dermal absorption, ingestion was the primary human exposure pathway for heavy metals in the Songhua River Basin, with exposure from water ingestion being slightly larger than that from the riparian soil. Risks associated with cancer and non-carcinogenic outcomes from the Songhua River were overall lower than those reported for the Yangtze River and Huaihe River, but higher than those of the Liujiang River [45-47]. The $C R$ of heavy metals in water $\left(C R_{w-i n}=1.60 \times 10^{-6}\right)$ indicated a possible elevated cancer risk associated with consuming water from the Songhua River, especially the case for water abstracted from the Harbin section that had the highest levels of $\mathrm{Cd}$ reported in this study. While direct ingestion is likely to be the most significant exposure route, this study cannot be viewed as an overall health risk assessment due to other pathways such as dietary and inhalation exposure being omitted at present. 
Table 3. Hazard quotient and carcinogenic risk for each element and exposure pathway.

\begin{tabular}{|c|c|c|c|c|c|c|c|c|c|c|c|c|c|c|}
\hline Element & $R f D_{i n}$ & $R f D_{\text {derm }}$ & $S F$ & $C D I_{w-i n}$ & $C D I_{s-i n}$ & $C D I_{w-\text { derm }}$ & $C D I_{s-\text { derm }}$ & $C D I_{i n}$ & $C D I_{\text {derm }}$ & $H Q_{i n}$ & $H Q_{\text {derm }}$ & $H I$ & $C R_{i n}$ & $C R_{\text {derm }}$ \\
\hline $\mathrm{Cu}$ & 0.04 & 0.012 & - & $2.49 \times 10^{-5}$ & $2.89 \times 10^{-5}$ & $7.34 \times 10^{-10}$ & $1.05 \times 10^{-6}$ & $5.38 \times 10^{-5}$ & $1.05 \times 10^{-6}$ & $1.35 \times 10^{-3}$ & $8.74 \times 10^{-5}$ & $1.43 \times 10^{-3}$ & - & - \\
\hline $\mathrm{Cr}$ & 0.003 & 0.015 & - & $8.87 \times 10^{-6}$ & $1.18 \times 10^{-4}$ & $4.13 \times 10^{-9}$ & $4.26 \times 10^{-6}$ & $1.27 \times 10^{-4}$ & $4.26 \times 10^{-6}$ & $4.22 \times 10^{-2}$ & $2.84 \times 10^{-4}$ & $4.25 \times 10^{-2}$ & - & - \\
\hline $\mathrm{Zn}$ & 0.3 & 0.06 & - & $5.00 \times 10^{-5}$ & $2.31 \times 10^{-4}$ & $6.64 \times 10^{-9}$ & $8.37 \times 10^{-6}$ & $2.81 \times 10^{-4}$ & $8.37 \times 10^{-6}$ & $9.37 \times 10^{-4}$ & $1.40 \times 10^{-4}$ & $1.08 \times 10^{-3}$ & - & - \\
\hline $\mathrm{Pb}$ & 0.001 & $4 \times 10^{-4}$ & - & $6.88 \times 10^{-6}$ & $2.98 \times 10^{-5}$ & $5.20 \times 10^{-11}$ & $1.08 \times 10^{-6}$ & $3.76 \times 10^{-5}$ & $1.08 \times 10^{-6}$ & $3.67 \times 10^{-2}$ & $2.70 \times 10^{-3}$ & $3.94 \times 10^{-2}$ & - & - \\
\hline $\mathrm{Ni}$ & 0.02 & 0.005 & - & $6.51 \times 10^{-6}$ & $3.77 \times 10^{-5}$ & $5.76 \times 10^{-11}$ & $1.36 \times 10^{-6}$ & $4.42 \times 10^{-5}$ & $1.36 \times 10^{-6}$ & $2.21 \times 10^{-3}$ & $2.73 \times 10^{-4}$ & $2.48 \times 10^{-3}$ & - & - \\
\hline $\mathrm{Cd}$ & $5 \times 10^{-4}$ & $5 \times 10^{-6}$ & 6.1 & $2.62 \times 10^{-7}$ & $4.89 \times 10^{-7}$ & $4.65 \times 10^{-11}$ & $1.77 \times 10^{-8}$ & $7.51 \times 10^{-7}$ & $1.77 \times 10^{-8}$ & $1.50 \times 10^{-3}$ & $3.54 \times 10^{-3}$ & $5.05 \times 10^{-3}$ & $4.58 \times 10^{-6}$ & $1.08 \times 10^{-7}$ \\
\hline
\end{tabular}




\subsection{Analysis of Sources of Heavy Metal Pollution}

Identifying sources of heavy metals is critical to effectively reducing pollution and human health risks $[1,5]$. In this study, Pearson correlation analysis coupled with principal component analysis $(P C A)$ was used to analyze the sources of heavy metals in the water and sediments of the Songhua River. The variables were further explained by varimax rotation.

Three factors were extracted from the water, accounting for $80.6 \%$ of the total variance. As illustrated in Figure 4a. Factor 1 (PC1), which had the highest cumulative contribution rate accounting for $49.9 \%$ of the variance, was heavily weighted by $\mathrm{Cu}, \mathrm{Cr}$, and $\mathrm{Ni}$ (loadings were greater than 0.80). There were significant correlations among these three elements (Table S6), while $\mathrm{Cu}, \mathrm{Cr}$, and $\mathrm{Ni}$ were significantly higher than the environmental background values $(p<0.01)$ [37]. Industrial production activities such as metalworking, electroplating and machinery manufacture use raw materials containing heavy metals such as $\mathrm{Cr}, \mathrm{Cu}$ and $\mathrm{Ni}[8,31,44]$. Therefore, it is inferred that PC1 represented the influence of the industrial production activities. Factor 2 (PC2), had a high loading of $\mathrm{Pb}(0.81)$ and $\mathrm{Zn}(0.68)$ and accounted for $16.9 \%$ of the total variance. Albasel and Cottenie had found that the contents of $\mathrm{Pb}$ and $\mathrm{Zn}$ rapidly decrease with increasing distance from roads [48]. Automobile exhaust and the wear of vehicle components will cause the accumulation of heavy metals, especially the content of $\mathrm{Pb}$ which until recent times was closely related to motor vehicles [16]. In addition, the application of pesticides and insecticides containing $\mathrm{Pb}$ and $\mathrm{Zn}$ could affect environmental safety in water due to their input through soil runoff and return flows $[8,49]$. Therefore, it was suggested that PC2 might be mainly affected by traffic and agricultural sources. Factor 3 (PC3) had a high loading of $\mathrm{Cd}$ accounting for $13.8 \%$ of the total variance. Cd was generally associated with the industries including electronics, printing and dyeing, electroplating chemical industry, as well as from the excessive use of phosphate fertilizers [8]. Therefore, PC3 might be attributable to both industrial and agricultural sources.
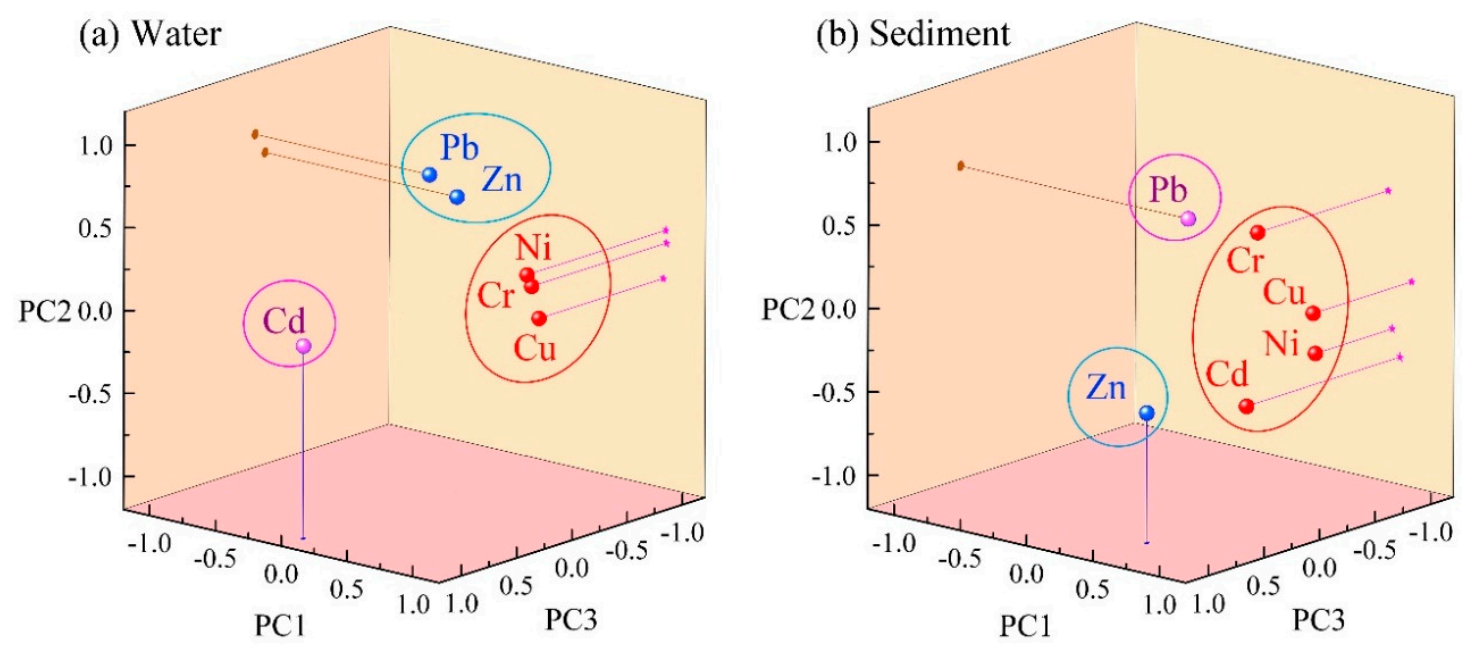

Figure 4. Load diagram of water (a) and sediment (b) principal component factor.

For sediment, three factors were extracted, accounting for $82.9 \%$ of the total variance. Individually, Factor 1 (PC1) had the high loading of $\mathrm{Cu}, \mathrm{Ni}, \mathrm{Cd}$ and $\mathrm{Cr}$ accounted for $49.1 \%$ of the variance as illustrated in Figure $4 \mathrm{~b}$. The concentrations of $\mathrm{Cu}$ and $\mathrm{Ni}$ were lower than the background value at a majority of the sampling sites, indicating geogenic sources of $\mathrm{Cu}$ and $\mathrm{Ni}$. Elevated concentrations of Ni were found within the industrial zones at S5 (Harbin), S9 and S12 (Jiamusi). Given that Ni, $\mathrm{Cd}$ and $\mathrm{Cr}$ were mainly used in electroplating, electronics, printing and dyeing [8,50], it was speculated that PC1 may represent a combination of natural sources and industrial emissions. The cumulative contribution rate of Factor 2 (PC 2) was $20.0 \%$, with a high load of $\mathrm{Pb}$, which may have largely originated from gasoline containing lead in the last century. Due to its environmental persistence, $\mathrm{Pb}$ is 
still an important indicator of transportation sources [21,48]. Moreover, the bioavailable form of $\mathrm{Pb}$ in the Songhua River sediments accounted for over $55 \%$, and demonstrated the anthropogenic influences on Pb levels in the sediments [51]. Thus, the PC2 is likely from traffic sources. Factor 3 (PC3) had a high loading of $\mathrm{Zn}$ accounted for $13.8 \%$ of the variance. The concentration of $\mathrm{Zn}$ in the sediment samples is correlated to those measured in the water $(R=0.623, p<0.05)$, indicating that they possibly have some similar sources (agriculture and transportation sources). In addition, $\mathrm{Zn}$ can be also derived from industrial processes such as mechanical processing, steel smelting, etc. [8,31]. It was concluded that the industrial, agriculture and transportation emissions together consist of the PC3.

The source apportionment confirmed that agriculture and industry were the main sources of heavy metals in the Songhua River basin. Thus, optimization and control of agricultural practices such as adopting precision agriculture approaches to chemical usage would aid in pollution mitigation. Due to the dominance of agricultural land use in the catchment, the potential for pollution reduction is considerable. At the same time, there are opportunities to adapt industrial processes and waste-management approaches to improve their environmental sustainability. This is especially pertinent to large urban areas such as Harbin. It is also imperative to improve the regulation of industrial units outside the main urban areas where clandestine discharges are likely to be more prevalent to improve the overall pollution level of locations such as S9.

\section{Conclusions}

The results of tests on the Songhua River water, sediments and soils confirmed that environmental pollution should be considered in a wholistic manner given the spatial variability of sources, interactions between pathways of exposure, as well as the non-linearity of the exposure term. Overall, the possibility of non-carcinogenic risk in the Songhua River was found to be very low. However, the cancer risk associated with consumption of the river water was slightly elevated above the cancer risk threshold. This cancer risk was mainly attributable to the presence of $\mathrm{Cd}$ in the water, and further work is required to understand the efficacy of the current water treatment regime for the removal or dilution of $\mathrm{Cd}$ and other potential pollutants associated with human health. The multi-media analysis indicated a significant accumulation of metals, particularly $\mathrm{Cd}$ and $\mathrm{Zn}$, over time. Industrial emissions are likely to be the primary source of the observed heavy metal enrichment. $\mathrm{Zn}$ and $\mathrm{Pb}$ are also likely to have been derived from agricultural activities and transportation. Agricultural sources of $\mathrm{Cd}$ also cannot be ignored. Optimization and control of agricultural management with a focus on precision agriculture approaches could be one way to reduce pollution discharges. By adopting a more wholistic multi-media, multi-exposure approach to risk assessment, we have obtained a more comprehensive understanding of the interaction between local human activities and the riverine environment. This improved understanding helps aid mitigation responses as well as highlighting important knowledge gaps for future investigation.

Supplementary Materials: The following are available online at http:/www.mdpi.com/1660-4601/17/5/1766/s1, Table S1: Distribution of sampling sites of the Songhua River; Table S2: Classifications of heavy metal pollution degree in drinking water; Table S3: Classifications of heavy metal pollution degree; Table S4: Worldwide average concentration of trace elements in sediment from major river of the world $\left(\mathrm{mg} \mathrm{kg}^{-1}\right)$; Table S5: The single contamination factor $\left(P_{i}\right)$ of sediment and riparian soil in Songhua River; Table S6: Pearson correlation matrix for heavy metals in surface sediments of the Songhua River.

Author Contributions: Conceptualization, S.C. and L.A.; methodology, Q.F., R.H. and Z.Z.; supervision and validation, S.C. and L.A.; data curation, K.L.; investigation, F.Z. and S.G.; experiments, F.Z. and K.L.; writing — original draft, K.L.; writing—review and editing, S.C., R.H. and L.A. All authors have read and agreed to the published version of the manuscript.

Funding: This research was funded by the National Key Research and Development Program of China (2017YFC0404503), the National Natural Science Foundation of China (No. 51779047), the Excellent Youth Science Foundation of Heilongjiang Province (YQ2019E001) and the Academic Backbone Project of Northeast Agricultural University (No.17XG04).

Conflicts of Interest: The authors declare no conflict of interest. 


\section{References}

1. Li, M.; Zhang, Q.; Sun, X.; Karki, K.; Zeng, C.; Aastha, R.B.; Zhang, F. Heavy metals in surface sediments in the trans-Himalayan Koshi River catchment: Distribution, source identification and pollution assessment. Chemosphere 2020, 244, 125410. [CrossRef] [PubMed]

2. Yan, B.; Xu, D.; Chen, T.; Yan, Z.; Li, L.; Wang, M. Leachability characteristic of heavy metals and associated health risk study in typical copper mining-impacted sediments. Chemosphere 2020, 239, 124748. [CrossRef] [PubMed]

3. Qu, L.; Huang, H.; Xia, F.; Liu, Y.; Dahlgren, R.A.; Zhang, M.; Mei, K. Risk analysis of heavy metal concentration in surface waters across the rural-urban interface of the Wen-Rui Tang River, China. Environ. Pollut. 2018, 237, 639-649. [CrossRef] [PubMed]

4. Zeng, X.; Liu, Y.; You, S.; Zeng, G.; Li, F. Spatial distribution, health risk assessment and statistical source identification of the trace elements in surface water from the Xiangjiang river, China. Environ. Sci. Pollut. Res. 2015, 22, 9400-9412. [CrossRef]

5. Xiao, J.; Wang, L.; Deng, L.; Jin, Z. Characteristics, sources, water quality and health risk assessment of trace elements in river water and well water in the Chinese Loess Plateau. Sci. Total Environ. 2019, 650, $2004-2012$. [CrossRef]

6. Li, Z.; Feng, X.; Li, G.; Bi, X.; Zhu, J.; Qin, H.; Dai, Z.; Liu, J.; Li, Q.; Sun, G. Distributions, sources and pollution status of 17 trace metal/metalloids in the street dust of a heavily industrialized city of central China. Environ. Pollut. 2013, 182, 408-416. [CrossRef]

7. Zhao, L.; Gong, D.; Zhao, W.; Lin, L.; Yang, W.; Guo, W.; Tang, X.; Li, Q. Spatial-temporal distribution characteristics and health risk assessment of heavy metals in surface water of the Three Gorges Reservoir, China. Sci. Total Environ. 2020, 704, 134883. [CrossRef]

8. Cui, S.; Zhang, F.; Hu, P.; Hough, R.; Fu, Q.; Zhang, Z.; An, L.; Li, Y.; Li, K.; Liu, D.; et al. Heavy metals in sediment from the urban and rural rivers in Harbin City, Northeast China. Int. J. Environ. Res. Public Health 2019, 16, 4313. [CrossRef]

9. Yan, N.; Liu, W.; Xie, H.; Gao, L.; Han, Y.; Wang, M.; Li, H. Distribution and assessment of heavy metals in the surface sediment of Yellow River, China. J. Environ. Sci. China 2016, 39, 45-51. [CrossRef]

10. Chen, R.; Chen, H.; Song, L.; Yao, Z.; Meng, F.; Teng, Y. Characterization and source apportionment of heavy metals in the sediments of Lake Tai (China) and its surrounding soils. Sci. Total Environ. 2019, 694, 133819. [CrossRef]

11. Zhang, W.; Feng, H.; Chang, J.; Qu, J.; Xie, H.; Yu, L. Heavy metal contamination in surface sediments of Yangtze River intertidal zone: An assessment from different indexes. Environ. Pollut. 2009, 157, 1533-1543. [CrossRef] [PubMed]

12. Chen, Y.; Jiang, Y.; Huang, H.; Mou, L.; Ru, J.; Zhao, J.; Xiao, S. Long-term and high-concentration heavy-metal contamination strongly influences the microbiome and functional genes in Yellow River sediments. Sci. Total Environ. 2018, 637, 1400-1412. [CrossRef] [PubMed]

13. Chai, L.; Li, H.; Yang, Z.; Min, X.; Liao, Q.; Liu, Y.; Men, S.; Yan, Y.; Xu, J. Heavy metals and metalloids in the surface sediments of the Xiangiang River, Hunan, China: Distribution, contamination, and ecological risk assessment. Environ. Sci. Pollut. Res. 2017, 24, 874-885. [CrossRef] [PubMed]

14. Dong, W.; Zhang, Y.; Quan, X. Health risk assessment of heavy metals and pesticides: A case study in the main drinking water source in Dalian, China. Chemosphere 2020, 242, 125113. [CrossRef]

15. Badawy, W.M.; Ghanim, E.H.; Duliu, O.G.; El Samman, H.; Frontasyeva, M.V. Major and trace element distribution in soil and sediments from the Egyptian central Nile Valley. J. Afr. Earth Sci. 2017, 131, 53-61. [CrossRef]

16. Turer, D.; Maynard, J.B.; Sansalone, J.J. Heavy metal contamination in soils of urban highways: Comparison between runoff and soil concentrations at Cincinnati, Ohio. Water Air Soil Pollut. 2001, 132, $293-314$. [CrossRef]

17. Wang, F.; Huang, C.; Chen, Z.; Bao, K. Distribution, ecological risk assessment, and bioavailability of cadmium in soil from Nansha, Pearl River Delta, China. Int. J. Environ. Res. Public Health 2019, 16, 3637. [CrossRef] 
18. Minh, N.D.; Hough, R.L.; Nyberg, Y.; Vinh, N.C.; Khai, N.M.; Öborn, I. Assessing dietary exposure to cadmium in a metal recycling community in Vietnam: Age and gender aspects. Sci. Total Environ. 2012, 416, 164-171. [CrossRef]

19. Ma, W.; Liu, L.; Qi, H.; Zhang, Z.; Song, W.; Shen, J.; Chen, Z.; Ren, N.; Grabuski, J.; Li, Y. Polycyclic aromatic hydrocarbons in water, sediment and soil of the Songhua River Basin, China. Environ. Monit. Assess. 2013, 185, 8399-8409. [CrossRef]

20. An, Y.; Zou, Z.; Li, R. Water quality assessment in the Harbin Reach of the Songhuajiang River (China) based on a fuzzy rough set and an attribute recognition theoretical model. Int. J. Environ. Res. Public Health 2014, 11, 3507-3520. [CrossRef]

21. Sun, C.; Zhang, Z.; Cao, H.; Xu, M.; Xu, L. Concentrations, speciation, and ecological risk of heavy metals in the sediment of the Songhua River in an urban area with petrochemical industries. Chemosphere 2019, 219, 538-545. [CrossRef] [PubMed]

22. Lin, C.; He, M.; Zhou, Y.; Guo, W.; Yang, Z. Distribution and contamination assessment of heavy metals in sediment of the Second Songhua River, China. Environ. Monit. Assess. 2008, 137, 329-342. [CrossRef] [PubMed]

23. Shen, Y.; Tan, L.; Shan, P.; Cao, H.; Deng, H. Analysis of the potential contamination risk of riverside key monitored enterprises on the aquatic environment of the Songhua River Basin. Acta Ecol. Sin. 2015, 36, 2732-2739. (In Chinese)

24. State Environmental Protection Administration of China (SEPAC). Technical Specifications for Surface Water and Wastewater Monitoring; HJ_T91-2002; China Environmental Science Press: Beijing, China, 2002.

25. State Environmental Protection Administration of China (SEPAC). Environmental Quality Standard for Soil Environmental Quality Risk Control Standard for Soil Contamination of Agricultural Land; GB15618-2018; China Environmental Science Press: Beijing, China, 2018.

26. State Environmental Protection Administration of China (SEPAC). Water and Wastewater Monitoring and Analysis Methods; China Environmental Science Press: Beijing, China, 2002.

27. Mohan, S.V.; Nithila, P.; Reddy, S.J. Estimation of heavy metals in drinking water and development of heavy metal pollution index. J. Environ. Sci. Health Part A 1996, 31, 283-289. [CrossRef]

28. Chinese Ministry of Health (CMH), National Standardization Administration of China. Standards for Drinking Water Quality; GB5749-2006; Standards Press of China: Beijing, China, 2006.

29. Nemerow, N.L.C. Scientific Stream Pollution Analysis; Scripta Book Company: Washington, DC, USA, 1974.

30. Memoli, V.; Esposito, F.; Panico, S.C.; De Marco, A.; Barile, R.; Maisto, G. Evaluation of tourism impact on soil metal accumulation through single and integrated indices. Sci. Total. Environ. 2019, 682, 685-691. [CrossRef]

31. Shaheen, A.; Iqbal, J.; Hussain, S. Adaptive geospatial modeling of soil contamination by selected heavy metals in the industrial area of Sheikhupura, Pakistan. Int. J. Environ. Sci. Technol. 2019, 16, 4447-4464. [CrossRef]

32. China National Environmental Monitoring Centre (CNEMC). Background Values of Soil Elements in China; China Environmental Press: Beijing, China, 1990.

33. US Environmental Protection Agency (US EPA). Risk Assessment Guidance for Superfund. Volume I. Human Health Evaluation Manual (Part A); US Environmental Protection Agency: Washington DC, USA, 1989.

34. State Environmental Protection Administration of China (SEPAC). Technical Guidelines for Risk Assessment of Contaminated Sites; HJ35.3-2104; China Environmental Science Press: Beijing, China, 2014.

35. US Environmental Protection Agency (US EPA). Risk Assessment Guidance for Superfund. Volume I. Human Health Evaluation Manual (Part E, Supplemental Guidance for Dermal Risk Assessment); US Environmental Protection Agency: Washington, DC, USA, 2004.

36. US Environmental Protection Agency (US EPA). Supplemental Guidance for Developing Soil Screening Levels for Superfund Sites. Office of Soild Waste and Emergency Response; US Environmental Protection Agency: Washington, DC, USA, 2001.

37. Li, J.; Zheng, C. Environmental Background Data Handbook; China Environmental Science Press: Beijing, China, 1989.

38. Wu, X.; Wang, S.; Chen, H.; Jiang, Z.; Chen, H.; Gao, M.; Bi, R.; Klerks, P.; Wang, H.; Luo, Y.; et al. Assessment of metal contamination in the Hun River, China, and evaluation of the fish Zacco platypus and the snail Radix swinhoei as potential biomonitors. Environ. Sci. Pollut. Res. 2017, 24, 6512-6522. [CrossRef]

39. State Environmental Protection Administration of China (SEPAC). Environmental Quality Standards for Surface Water; GB 3838-2002; China Environmental Science Press: Beijing, China, 2002. 
40. Zhang, F.; Yan, B.; Zhu, L. Speciation of heavy metals in sediment of the Songhua River, Northeast of China. J. Agro-Environ. Sci. 2010, 29, 163-167. (In Chinese)

41. LeCloatec, M.F.; Bonete, P.H.; Lestel, L.I.; Ayrault, S. Sedimentary record of metal contamination in the Seine River during the last century. Phys. Chem. Earth 2011, 36, 515-529.

42. Roig, N.; Sierra, J.; Moreno Garrido, I.; Nieto, E.; Gallego, E.P.; Schuhmacher, M.; Blasco, J. Metal bioavailability in freshwater sediment samples and their influence on ecological status of river basins. Sci. Total Environ. 2016, 540, 287-296. [CrossRef]

43. Xia, X.; Yang, Z.; Cui, Y.; Li, Y.; Hou, Q.; Yu, T. Soil heavy metal concentrations and their typical input and output fluxes on the southern Songnen Plain, Heilongjiang Province, China. J. Geochem. Explor. 2014, 139, 85-96. [CrossRef]

44. Li, J.; Pu, L.; Zhu, M.; Liao, Q.; Wang, H.; Cai, F. Spatial pattern of heavy metal concentration in the soil of rapid urbanization area: A case of Ehu Town, Wuxi City, Eastern China. Environ. Earth Sci. 2014, 71, 3355-3362. [CrossRef]

45. Wu, B.; Zhao, D.; Jia, H.; Zhang, Y.; Zhang, X.; Cheng, S. Preliminary risk assessment of trace metal pollution in surface water from Yangtze River in Nanjing Section, China. Bull. Environ. Contam. Toxicol. 2009, 82, 405-409. [CrossRef] [PubMed]

46. Wang, J.; Liu, G.; Liu, H.; Lam, P.K.S. Multivariate statistical evaluation of dissolved trace elements and a water quality assessment in the middle reaches of Huaihe River, Anhui, China. Sci. Total Environ. 2017, 583, 421-431. [CrossRef]

47. Li, S.; Xiong, J.; Deng, C.; Wang, X. The assessment of the heavy metal pollution and health risks in the Liujiang River, Xijiang Region. Guangxi Sci. 2018, 25, 393-399. (In Chinese)

48. Albasel, N.; Cottenie, A. Heavy metal contamination near major highways, industrial and urban areas in Belgian grassland. Water Air Soil Pollut. 1985, 24, 103-109. [CrossRef]

49. Wuana, R.A.; Okieimen, F.E. Heavy metals in contaminated soils: A review of sources, chemistry, risks and best available strategies for remediation. ISRN Ecol. 2011. [CrossRef]

50. Jin, Y.; Liu, L.; Zhang, S.; Tao, B.; Tao, R.; He, X.; Qu, L.; Huang, J.; Wang, X.; Fu, Z. Chromium alters lipopolysaccharide-induced inflammatory responses both in vivo and in vitro. Chemosphere 2016, 148, 436-443. [CrossRef]

51. Li, Z. Heavy Metal Concentration, Speciation and Ecological Risk Assessment of Surface Sediments in Songhua River. Master's Thesis, Lanzhou University of Technology, Lanzhou, China, March 2019. (In Chinese). 